\section{ESPORTE E LAZER NO PLANO INDIVIDUAL DE ATENDIMENTO DE ADOLESCENTES EM CUMPRIMENTO DE MEDIDA SOCIOEDUCATIVA DE INTERNAÇÃO}

\author{
SPORT AND LEISURE IN THE INDIVIDUAL PLAN OF ADOLESCENT \\ CARE IN COMPLIANCE WITH COURT-MANDATED SOCIAL-EDUCATIVE \\ INTERNMENT C P
}

DEPORTE Y RECREACIÓN EN EL PLAN INDIVIDUAL DE ASISTENCIA

PARA ADOLESCENTES EN CUMPLIMIENTO DE MEDIDA

SOCIOEDUCATIVA DE INTERNACIÓN FÍSICA C C田

doi' https://doi.org/10.22456/1982-8918.101588

(D) Ueliton Peres de Oliveira*<uelitonoliveira@sesp.mt.gov.br>

Willian Lazaretti da Conceição** <lazaretti@ufpa.br>

José Tarcísio Grunnenvaldt* <jotagrun@hotmail.com>

iD Raul Angel Carlos Olivera*** <raulcarlos@unemat.br>

Diller Silva Reverdito**** <rsreverdito@unemat.br>

\footnotetext{
* Universidade Federal de Mato Grosso. Cuiabá, MT, Brasil.

** Universidade Federal do Pará. Belém, PA, Brasil.

*** Universidade do Estado de Mato Grosso. Sinop, MT, Brasil.

**** Universidade do Estado de Mato Grosso, Cáceres, MT, Brasil.
}

Resumo: Esta pesquisa documental tem por objetivo compreender o acesso ao esporte e lazer na trajetória de adolescentes em cumprimento de medida socioeducativa de internação no estado de Mato Grosso. Foram analisados 36 Planos Individuais de Atendimento (PIA) de sete Centros de Atendimento Socioeducativo, elaborados entre os anos de 2017-2018 e disponibilizados pela Gestão Estadual do Sistema para Infância e Adolescência - SIPIA/SINASE/MT. Os dados relacionados aos eixos esporte e lazer foram analisados através da análise de conteúdo. O perfil dos adolescentes retrata os problemas socioeconômicos e de vulnerabilidade social presentes na contemporaneidade. A partir das categorias de análise observou-se a restrita oferta dessas políticas de atendimento na trajetória dos adolescentes. Conclui-se que o cumprimento da medida socioeducativa de internação propiciou maior acesso aos espaços, equipamentos e conteúdos de esporte e lazer aos adolescentes, se comparado com suas vivências anteriores à aplicação da medida.

Palavras chave: Adolescente. Esportes. Atividades de Lazer. Vulnerabilidade Social.
Recebido em: 02/04/2020 Aprovado em: 10/06/2020 Publicado em: 30/07/2020

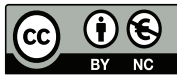

Este é um artigo publicado sob a licença Creative Commons atribuição Não Comercial 4.0 (CC BY-NC 4.0).

elSSN: 1982-8918 


\section{INTRODUÇÃO}

Nas últimas décadas tem-se observado a crescente criminalização da população jovem advinda de contextos de vulnerabilidade social no Brasil, invisíveis perante as políticas públicas de atenção básica (TEJADAS, 2008; OLIVEIRA; TURECK, 2019). Esses sujeitos ganham notoriedade somente após o cometimento de ato infracional e a aplicação das medidas socioeducativas (ASSIS; CONSTANTINO, 2005), sendo transferido ao adolescente a culpa pelo atual cenário de violência no país (GADEA et al., 2017).

As medidas socioeducativas aplicáveis aos adolescentes autores de ato infracional (advertência, obrigação de reparar o dano, prestação de serviço à comunidade, liberdade assistida, semiliberdade e internação) estão dispostas no 'Art. 112 ' do Estatuto da Criança e Adolescente (ECA) e devidamente regulamentadas pela Lei 12.594/12 que instituiu o Sistema Nacional de Atendimento Socioeducativo (SINASE) (BRASIL, 1990; 2012). Em relação à medida socioeducativa de internação, contexto que permeia as discussões deste estudo, deve-se considerar os princípios da 'brevidade', relacionada ao tempo de internação, a 'excepcionalidade', devendose esgotar demais possibilidades de se aplicar outra medida socioeducativa que seja menos gravosa, e 'o respeito à condição peculiar de pessoa em desenvolvimento (BRASIL, 1990). Desta forma, mesmo presente o aspecto sancionatório, há de prevalecer o caráter pedagógico que potencialize as ações de socioeducação previstas nos programas que executam as medidas socioeducativas.

Dentre as atividades garantidas aos adolescentes em cumprimento de medida socioeducativa de internação, figuram o esporte e o lazer, conforme preconizado no SINASE (BRASIL, 2006). O esporte e o lazer compreendidos como fenômenos socioculturais, são dotados de um aspecto comum, o caráter pedagógico que permeia ambos (MARCELLINO, 1998; PIZANI; AMARAL; PAES, 2012; SILVA; MOREIRA, 2018). No entanto, ao passo que estudos apontam estes elementos como vias privilegiadas de educação no contexto da privação de liberdade, também sinalizam para a escassa oferta dessas políticas nas trajetórias desses sujeitos (SANIOTO, 2005; TEJADAS, 2008; CONCEIÇÃO, 2012; DOMINGOS, 2014; NOGUEIRA, 2016; CARNEIRO et al., 2016; TIELLET et al., 2017, SOUZA, 2018, TRENTIN; SILVESTRE; AMARAL, 2018).

O Plano Decenal de Atendimento Socioeducativo do Estado de Mato Grosso (2015/2024) (MATO GROSSO, 2014), diz contar com 101 profissionais de nível superior laborando diretamente nas Unidades do Sistema Socioeducativo, dos quais 21 correspondem ao perfil de Educador Físico. Considerando que o Relatório Anual do SINASE de 2017, elaborado pela Secretaria Nacional dos Direitos da Criança e Adolescente (BRASIL, 2019), evidencia que o Estado dispunha de oito Centros de Atendimento Socioeducativo (CASE) com 88 adolescentes em cumprimento de medida socioeducativa de Internação, têm-se a média de um (1) profissional de Educação Física para cada 4,2 adolescentes. Ainda, destaca-se que os Parâmetros da Gestão Pedagógica no Atendimento Socioeducativo, dispõe que os programas que executam as medidas socioeducativas devem garantir espaços para a prática 
de esportes e atividades de lazer devidamente equipados e em quantidade suficiente para o atendimento dos adolescentes (BRASIL, 2006).

A partir da conjuntura apresentada em relação a trajetória, o adolescente em conflito com a lei estaria fadado ao acesso as políticas de esporte e lazer somente a partir da aplicação da medida socioeducativa? Diante do exposto, este estudo objetiva compreender o acesso ao esporte e lazer de adolescentes em cumprimento de medida socioeducativa de internação no Estado de Mato Grosso. Espera-se que os resultados subsidiem políticas de atendimento ao adolescente, articuladas por um conjunto de ações governamentais e não governamentais, da União, estados, Distrito Federal e municípios (BRASIL, 1990).

\section{METODOLOGIA}

Trata-se de uma pesquisa documental (GIL, 2008) de abordagem qualitativa, a qual utilizou-se de documentos do tipo fonte secundária, a saber, o Plano Individual de Atendimento do Adolescente (PIA). Conforme preconizado no 'Capítulo IV' da Lei 12. 594/12 - SINASE (BRASIL, 2012), o PIA é um documento garantido no cumprimento das medidas socioeducativas, como instrumento de previsão, registro e gestão das atividades a serem desenvolvidas com o adolescente. Especificamente, para a medida socioeducativa de internação, o SINASE estabelece que o documento deve ser elaborado no prazo de até 45 dias da data do ingresso do adolescente, por profissionais que compõem a equipe técnica de referência e a participação direta do adolescente, pais e/ou responsáveis legais.

A elaboração do PIA estrutura-se em três momentos distintos após o adolescente adentrar a medida socioeducativa de internação. A priori, a equipe técnica de referência (Psicólogo, Assistente Social, Educador Físico, profissionais da saúde e educação) realiza o estudo de caso situacional do adolescente, que permite levantar um diagnóstico amplo da trajetória do sujeito. Após o diagnóstico, a equipe elabora a construção de metas a serem desenvolvidas durante o cumprimento da medida socioeducativa, considerando a sondagem de habilidades, aptidões e necessidades apontadas pelos adolescentes e familiares no estudo de caso situacional. Por fim, a equipe técnica realiza o acompanhamento de todo o percurso do adolescente com o objetivo de avaliar o cumprimento da medida socioeducativa em suas diversas áreas (família, profissionalização, educação, religião, saúde, cultura, esporte e lazer).

Aos procedimentos para obtenção dos documentos, a gestão do Sistema de Informação para Infância e Adolescência (SIPIA), que detém e operacionaliza os dados referentes aos adolescentes em cumprimento de Medida Socioeducativa de Internação no Estado de Mato Grosso, disponibilizou 36 PIA elaborados entre os anos de 2017 e 2018, oriundos de sete Centros de Atendimento Socioeducativo do Estado que atendem a medida socioeducativa de internação. A escolha dos documentos ocorreu exclusivamente sobre responsabilidade da Gestão do SIPIA/ SINASE/MT, de forma aleatória e sem qualquer identificação dos adolescentes e/ou familiares. A pesquisa foi submetida ao Comitê de Ética em Pesquisa - CEP/SAÚDE/ 
UFMT (CAAE: 03382918.9.0000.8124) e aprovada no dia 26 de dezembro de 2018, conforme parecer $\mathrm{n}^{\circ} 3.102 .411$.

\subsection{ANÁLISE DOS DADOS}

Os dados relacionados ao perfil dos sujeitos foram extraídos do campo "Estudo de Caso Situacional do Adolescente" do PIA, destarte, sumarizados e expostos em tabela. Para tratarmos os dados específicos aos eixos Esporte e Lazer, utilizou-se o método da análise de conteúdo (BARDIN, 2011). Nesse sentido, na primeira fase denominada de pré-análise, realizou-se a leitura flutuante dos documentos - PIA, com o fito de sistematizar as ideias iniciais e estabelecer indicadores para interpretação dos dados. Na segunda fase, os dados foram organizados em Unidades de Sentido/ Registro, agrupados tematicamente em duas categorias de análise: 'Acesso às práticas de esporte e lazer antes da aplicação da medida socioeducativa' e 'Acesso às práticas de esporte e lazer no cumprimento da medida socioeducativa'. Na terceira fase, realizou-se o tratamento, inferências e interpretação dos dados relacionados às categorias de análise.

\section{RESULTADOS E DISCUSSÃO}

A partir do Estudo de Caso Situacional do adolescente contido no PIA, foi possível identificar o perfil de 36 adolescentes em cumprimento de medida socioeducativa de internação no Estado de Mato Grosso (Tabela 1). Em sua maioria, adolescentes do sexo masculino, com idades entre 16 e 17 anos, reincidentes e cumprindo medida socioeducativa de internação pela prática de roubo, usuários de diversos tipos de drogas, com baixa escolaridade e histórico de evasão escolar. Observou-se ainda, o escasso acesso às políticas públicas culturais voltadas a esse público e baixa inserção no mercado de trabalho, que geralmente se restringe à informalidade, o que reflete a quase inexistência de qualificação profissional dos sujeitos.

Tabela 1 - Perfil dos adolescentes

\begin{tabular}{llcc}
\hline PERFIL & VARIÁVEL & QTD. & $\%$ \\
\hline \multirow{2}{*}{ Sexo } & Masculino & 28 & $77,78 \%$ \\
& Feminino & 8 & $22,22 \%$ \\
\hline \multirow{3}{*}{ Idade } & 17 anos & 17 & $47,22 \%$ \\
& 16 anos & 10 & $27,78 \%$ \\
& 15 anos & 7 & $19,44 \%$ \\
\multirow{2}{*}{ Uso de Drogas } & 14 anos & 2 & $5,56 \%$ \\
\hline \multirow{2}{*}{ Tipos de drogas utilizadas* } & Usuários & 33 & $91,67 \%$ \\
& Não usuários & 3 & $8,33 \%$ \\
\hline & Caconha & - & $96,96 \%$ \\
& Álcool & - & $63,63 \%$ \\
& Cocaína & - & $57,57 \%$ \\
& Outras & - & $36,36 \%$ \\
\hline
\end{tabular}


Continuação da tabela 1.

\begin{tabular}{lllc}
\hline & $9^{\circ}$ Ano Ensino Fundamental & 9 & $25 \%$ \\
& $1^{\circ}$ Ano Ensino Médio & 8 & $22,22 \%$ \\
& $8^{\circ}$ Ano Ensino Fundamental & 6 & $16,66 \%$ \\
& $7^{\circ}$ Ano Ensino Fundamental & 5 & $13,89 \%$ \\
& $6^{\circ}$ Ano Ensino Fundamental & 3 & $8,33 \%$ \\
& Não informado & 2 & $5,56 \%$ \\
& $5^{\circ}$ Ano Ensino Fundamental & 1 & $2,78 \%$ \\
& $2^{\circ}$ Ano do Ensino Médio & 1 & $2,78 \%$ \\
& Não preenchido & 1 & $2,78 \%$ \\
\hline \multirow{2}{*}{ Histórico de evasão escolar } & Evadidos & 30 & $83,33 \%$ \\
& Não evadidos & 6 & $16,67 \%$ \\
\hline \multirow{2}{*}{ Inserção no mercado de trabalho } & Nunca trabalhou & 21 & $58,33 \%$ \\
& Já trabalhou & 15 & $41,67 \%$ \\
\hline \multirow{2}{*}{ Rursos profissionalizantes } & Nenhum curso & 27 & $75 \%$ \\
& Já realizou & 9 & $25 \%$ \\
\hline \multirow{2}{*}{ Acesso a atividades culturais } & Nenhum & 22 & $61,11 \%$ \\
& Escasso & 14 & $38,89 \%$ \\
\hline \multirow{2}{*}{ Ato infracional cometido } & Roubo & 19 & $52,78 \%$ \\
& Não Informado & 8 & $22,22 \%$ \\
& Homicídio & 5 & $13,89 \%$ \\
& Tráfico de Drogas & 7 & $8,33 \%$ \\
& Reincidentes & $2,78 \%$ \\
\hline & Não informado de Homicídio & 4 & $11,12 \%$ \\
\hline
\end{tabular}

Fonte: Elaborada pelo autor.

Nota: * Houve adolescentes que manifestaram utilizar mais de um tipo de droga.

Os dados aqui expostos dialogam com os resultados de outras pesquisas que identificaram o perfil e trajetórias de adolescentes em conflito com a lei em diferentes contextos de medidas socioeducativas e regiões do país (FEIJÓ; ASSIS, 2004; ASSIS; CONSTANTINO, 2005; TEJADAS, 2008; GALLO; WILLIAMS, 2008; ZAPPE; RAMOS, 2010; JIMENEZ; MARQUES, 2018; OLIVERA; OLIVEIRA, 2019). Tais estudos evidenciam a escassa oferta de políticas de atenção básica na trajetória dos adolescente (escolarização, saúde, segurança, cultura, esporte e lazer), onde a associação desses fatores os expõem à contextos de vulnerabilidade que podem se configurar como possíveis riscos ao cometimento de ato infracional.

Aspectos do ambiente familiar também foram evidenciados na trajetória de vida desses sujeitos (Tabela 2). Em suma, adolescentes advindos de famílias monoparentais de baixa renda, com histórico de envolvimento com a criminalidade e pouco acesso aos programas assistenciais do governo. Nessa esteira, os resultados do estudo de Dib, Bazon e Silva (2012), apontam que certos fatores estáticos inerentes à família, como a monoparentalidade e histórico de criminalidade por parte de membros da família, constituem-se como fatores de risco a delinquência juvenil. Entretanto, considerando que o ambiente familiar também pode configurarse como um fator de proteção à conduta infracional (DIB; BAZON; SILVA, 2012; 
NUNES; ANDRADE; MORAIS, 2013), faz-se necessário à articulação de políticas de atendimento a ambos, seja antes e/ou durante o cumprimento de medida socioeducativa.

Tabela 2 - Aspectos relacionados às famílias dos adolescentes

\begin{tabular}{|c|c|c|c|}
\hline PERFIL & VARIÁVEL & QTD. & $\%$ \\
\hline \multirow{6}{*}{ Composição familiar } & Família Monoparental & 18 & $50 \%$ \\
\hline & Família Extensa & 7 & $19,45 \%$ \\
\hline & Família Nuclear & 3 & $8,33 \%$ \\
\hline & Reside Sozinho & 3 & $8,33 \%$ \\
\hline & Reside com companheiro (a) & 3 & $8,33 \%$ \\
\hline & Reside com amigos & 2 & 5,56 \\
\hline \multirow{5}{*}{ Renda familiar } & 1 a 2 Salários Mínimos & 17 & $47,22 \%$ \\
\hline & 2 a 3 Salários Mínimos & 9 & $25 \%$ \\
\hline & Ignorado & 7 & $19,44 \%$ \\
\hline & Menos de 1 Salário Mínimo & 2 & $5,56 \%$ \\
\hline & Mais de 3 Salários Mínimos & 1 & $2,78 \%$ \\
\hline \multirow{2}{*}{$\begin{array}{l}\text { Famílias inseridas em Programas } \\
\text { Assistenciais do Governo }\end{array}$} & Não Inseridas & 27 & $75 \%$ \\
\hline & Inseridas & 9 & $25 \%$ \\
\hline \multirow{2}{*}{$\begin{array}{l}\text { Histórico de envolvimento com a } \\
\text { criminalidade }\end{array}$} & Não informado & 20 & $55,56 \%$ \\
\hline & Envolvidas & 16 & $44,44 \%$ \\
\hline
\end{tabular}

Fonte: Elaborada pelo autor.

\subsection{ACESSO ÀS PRÁTICAS DE ESPORTE E LAZER ANTES DA APLICAÇÃO DA MEDIDA SOCIOEDUCATIVA}

Esta categoria de análise relaciona-se com as manifestações dos adolescentes acerca de suas vivências/experiências anteriores com as práticas esportivas (Tabela 3) e de lazer (Tabela 4), a qual compõe a parte diagnóstica do PIA elaborada pelos Profissionais de Educação Física dos Centros de Atendimento Socioeducativo de Mato Grosso.

Tabela 3 - Manifestações dos adolescentes sobre as práticas de esporte vivenciadas

\begin{tabular}{ll}
\hline MANIFESTAÇÕES* & $\%$ \\
\hline Não praticavam nenhum esporte & $44,44 \%$ \\
Futebol & $19,44 \%$ \\
Praticavam somente na escola & $16,67 \%$ \\
Futsal & $13,89 \%$ \\
Jogar bola na rua & $13,89 \%$ \\
Praticavam esportes em Projetos Socioesportivos & $11,11 \%$ \\
Basquete & $5,56 \%$ \\
Vôlei & $2,78 \%$ \\
Judô & $2,78 \%$ \\
Capoeira & $2,78 \%$ \\
Taekwondo & $2,78 \%$ \\
\hline
\end{tabular}


Chama atenção o percentual de adolescentes que declararam nunca terem praticado algum tipo de esporte $(n=44,44 \%)$. Dentre os principais motivos declarados estão à falta de acesso a espaços e equipamentos de esporte em suas comunidades, o envolvimento com o mundo do crime e o próprio desinteresse. A falta de acesso a essas políticas restringem as possiblidades dos adolescentes ressignificarem suas trajetórias, uma vez que não são oportunizados meios que ofereçam experiências de interação e sociabilidade para além das já vivenciadas em suas comunidades, com altos índices de violência (TEJADAS, 2008; GADEA et al., 2017).

A prevalência dos esportes coletivos tradicionais, como o futebol e futsal também foram evidenciados nas trajetórias dos adolescentes, sinalizando para um repertório restrito de conteúdos vivenciados. Este restrito conhecimento sobre tais conteúdos depauperam as concepções dos adolescentes sobre o que realmente é esporte, como observado em algumas manifestações, que apontaram o simples fato de 'jogar bola na rua' ( $n=13,89 \%$ ). Nesse sentido, considerando o esporte quanto conteúdo da Educação Física escolar, os adolescentes deveriam ter acesso a um ensino diversificado de conteúdos, ampliando suas concepções e possibilidades (PAES; BALBINO, 2009; SCAGLIA; REVERDITO; GALATTI, 2014; REVERDITO et al., 2016a).

A escola enquanto um espaço formativo do indivíduo tem se constituído como um dos poucos espaços que ainda propiciam vivências esportivas aos sujeitos, conforme observado nas manifestações dos adolescentes $(n=16,67 \%)$. Porém, a evasão escolar evidenciada nesta pesquisa $(n=83,33 \%)$, torna-se um entrave para consolidação dessas práticas. Estudos têm apontado que a maioria dos adolescentes em conflito com a lei evade precocemente da escola e adentram as medidas socioeducativas com significativa defasagem escolar (DIAS; ONOFRE, 2010; BAZON; SILVA; FERRARI, 2013; SILVA; BAZON, 2015), consequentemente, este fato restringe suas vivências esportivas que, em tese, deveriam acontecer de forma orientada no contexto escolar.

Para além da escola, os projetos socioesportivos constituem-se em espaços privilegiados ao propiciarem vivências esportivas aos adolescentes. Contudo, uma pequena parcela dos sujeitos da pesquisa teve acesso $(n=11,11 \%)$. Insta salientar que o cumprimento das medidas socioeducativas em meio aberto, 'Prestação de Serviço à Comunidade (PSC)' e 'Liberdade Assistida (LA)', sob responsabilidade dos municípios, através dos Centros de Referência Especializados de Assistência Social (CREAS), preveem a inserção dos adolescentes em Projetos Socioesportivos. Diante do exposto, considerando o alto índice de reincidência evidenciada nessa pesquisa ( $n=69,44 \%$ ), pode-se inferir que esses sujeitos somente tiveram acesso a tais projetos por estarem cumprindo alguma medida socioeducativa anterior a internação.

Segundo Machado, Galatti e Paes (2012, p. 165), "[...] os projetos sociais neste século XXI, configuram-se como uma prática cultural legitimada pela sociedade, pelo Estado e pelo mercado". Entretanto, tem-se observado a descontinuidade desses projetos socioesportivos, que duram por curtos períodos e prejudicam o atendimento as crianças e adolescentes por questões que perpassam por interesses da gestão pública, capacidade gestora (recursos humanos e técnicos especializados) e 
parcerias público-privadas (REVERDITO et al., 2016b; MACHADO et al., 2017), limitando ainda mais o acesso a tais práticas por parte dos adolescentes em conflito com a lei.

Quanto às vivências de lazer manifestadas pelos adolescentes, o panorama também apresenta um restrito repertório de conteúdos, espaços e equipamentos públicos disponibilizados aos sujeitos (Tabela 4), o que prejudica consideravelmente a 'educação para e pelo lazer' (MARCELLINO, 1996; 1998).

Tabela 4 - Manifestações dos adolescentes sobre as atividades de lazer vivenciadas

\begin{tabular}{lc|lc}
\hline \multicolumn{1}{c|}{ MANIFESTAÇÕES } & $\%$ & \multicolumn{1}{c}{ MANIFESTAÇÕES } & $\%$ \\
\hline Banho de rio & $27,78 \%$ & Acesso em Projetos Sociais & $5,56 \%$ \\
Jogar bola na rua & $22,22 \%$ & Dançar & $5,56 \%$ \\
Não reconhece nenhuma atividade & $19,44 \%$ & Frequentar Balneários & $2,78 \%$ \\
Festas noturnas & $16,67 \%$ & Ouvir Música & $2,78 \%$ \\
Videogame & $13,89 \%$ & Andar de Bicicleta & $2,78 \%$ \\
Cinema & $11,11 \%$ & Acessar Internet & $2,78 \%$ \\
Passear na praça & $11,11 \%$ & Tomar banho de piscina & $2,78 \%$ \\
Encontros com amigos & $11,11 \%$ & Capoeira & $2,78 \%$ \\
Encontros familiares & $8,33 \%$ & Ir ao Zoológico & $2,78 \%$ \\
Clubes & $8,33 \%$ & Andar de Skate & $2,78 \%$ \\
Assistir TV & $5,56 \%$ & Soltar pipa & $2,78 \%$ \\
Ficar na rua & $5,56 \%$ & Ler livros & $2,78 \%$ \\
Assistir filme em casa & $5,56 \%$ & Acesso através da Escola & $2,78 \%$ \\
\hline
\end{tabular}

Fonte: elaborado pelo autor.

Nota: Houve adolescentes que manifestaram vivenciar mais de uma atividade de lazer

De acordo com Marcellino (1996), ao considerar o lazer como via e objeto de educação, é necessário que os sujeitos sejam oportunizados a vivenciarem e se satisfazerem com os diferentes interesses abrangidos pelos conteúdos do lazer, sejam os artísticos, os intelectuais, os físicos, os manuais, os turísticos e sociais. Para tanto, o autor enfatiza que as pessoas "sejam estimuladas a participar e recebam o mínimo de orientação que Ihes permitam a opção" (MARCELLINO, 1996, p. 17), o que está em desacordo com os resultados encontrados.

Observa-se que as manifestações de lazer mais citadas pelos adolescentes, 'banho de rio' ( $n=27,78 \%$ ) e 'jogar bola na rua' ( $n=22,22 \%)$, estão relacionadas ao conteúdo de interesses físicos no tempo livre, que se desenrolam no cotidiano desses sujeitos sem qualquer orientação quanto aos potencias educativos do lazer. $\mathrm{Na}$ perspectiva do lazer segundo Marcellino (1996; 1998), como via e objeto de educação, a oportunidade de uma orientação mediadora poderia oferecer aos adolescentes uma experiência crítica, criativa e consciente, por conseguinte, oferecendo oportunidades para a formação de sujeitos autônomos e reflexivos, capazes de ressignificar seus modos de vida. Depois, a ocupação do tempo livre é reforçada sem a presença de um/a animador/a sociocultural, com destaque para as festas noturnas, videogame, cinema, passear na praça e encontrar com amigos.

Os animadores socioculturais são profissionais advindos de distintas áreas de atuação profissional (Pedagogia, Educação Física, Hotelaria, Turismo, dentre outros) 
e, ao assumirem postura de mediadores frente a tais práticas, tornam-se fundamentais para a democratização dos diferentes conteúdos do lazer através das relações estabelecidas com seu público (MARCELLINO et al., 2007; MARIANO; MARCELLINO, 2011). Desta forma, vislumbra-se que os contextos escolares e de projetos sociais são ambientes férteis para que a animação cultural possa se concretizar. Entretanto, apenas $5,56 \%$ dos adolescentes manifestaram terem tido acesso as práticas de lazer em projetos sociais e, surpreendentemente, somente $2,78 \%$ dos adolescentes declararam terem vivenciado práticas de lazer na escola. Este resultado nos permite destacar uma (a) escassa oferta de conteúdos diversificados de lazer nas trajetórias escolares de adolescentes em conflito com a lei e (b) dificuldade dos adolescentes em articularem suas concepções ante o fenômeno (CONCEIÇÃO, 2012; CARNEIRO et al., 2016). Estes fatores podem elucidar o número expressivo de adolescentes que não reconhecem práticas de lazer antes da aplicação da medida socioeducativa de internação $(n=19,44 \%)$.

Houve também manifestações consideráveis a respeito dos interesses sociais, caracterizados pelo convívio social, como frequentar festas noturnas ( $n=16,67 \%)$, encontros com amigos $(n=11,11 \%)$ e familiares $(n=8,33 \%)$. Chama a atenção constatar que uma parcela significativa de adolescentes frequentava festas noturnas, ampliando a situação de exposição a fatores mobilizadores de riscos sociais, como a ingestão de bebidas alcoólicas e drogas ilícitas. Nesse viés, estudo realizado com 63 adolescentes dos Centros de Atendimento Socioeducativo do Estado de Mato Grosso, identificou que uma grande parcela dos entrevistados fazia uso de álcool ( $n=65 \%$ ) e declararam usar drogas $(n=60 \%)$ antes da aplicação da medida socioeducativa, geralmente quando se reuniam com colegas em festas noturnas (OLIVERA; OLIVEIRA, 2019). Importante enfatizar que esses adolescentes, invisíveis aos olhos da sociedade, por vezes buscam seu protagonismo e pertencimento junto aos seus pares, que já apresentam histórico de envolvimento com as drogas e conduta infracional (JIMENEZ; MARQUES, 2018; KOSTULSKI et al., 2019; OLIVEIRA; TURECK, 2019), o que poderia explicar o fato de $91,67 \%$ dos sujeitos desta pesquisa serem usuários.

Outros conteúdos relacionados aos interesses artísticos, manuais, turísticos e intelectuais foram manifestados com menor expressividade. Insta registrar a baixa adesão à leitura, inerente aos interesses intelectuais $(n=2,78 \%)$. Este fato reafirma o fenômeno da evasão e significativa defasagem escolar entre adolescentes em conflito com a lei.

As restritas vivências de conteúdos do lazer aqui evidenciadas estão intrinsecamente relacionadas a escassa oferta de espaços e equipamentos públicos disponibilizados para essa população, advinda de contextos de vulnerabilidade social. Essa população geralmente se vê obrigada a migrar para as partes periféricas das cidades, o que dificulta o acesso aos espaços e equipamentos públicos específicos de lazer, considerando a centralização dos equipamentos em regiões com maior infraestrutura (MARCELLINO; BARBOSA; MARIANO, 2006; REVERDITO et al., 2012). Para Marcellino, Barbosa e Mariano (2006), a situação se agrava com a expansão da criação de novos espaços de lazer no ambiente urbano por parte da 
iniciativa privada, onde a maioria da população não dispõe de condições financeiras para frequentar, ficando a mercê da agenda de políticas de governo.

\subsection{ACESSO ÀS PRÁTICAS DE ESPORTE E LAZER NO CUMPRIMENTO DA MEDIDA SOCIOEDUCATIVA}

Esta categoria de análise relaciona-se com as atividades de esporte (Quadro 1) e de lazer (Quadro 2), disponibilizadas aos adolescentes durante o cumprimento da medida socioeducativa de internação. Compõe os campos 'Construção de Metas com o adolescente a partir do Estudo de Caso Situacional' e 'Acompanhamento do Percurso do Adolescente', contidos no PIA, elaborados pela Equipe Técnica de Referência dos Centros de Atendimento Socioeducativo do Estado de Mato Grosso.

Quadro 1 - Atividades relacionadas ao esporte evidenciadas na medida socioeducativa

\begin{tabular}{|c|}
\hline Práticas esportivas nas aulas de Educação Física \\
\hline Escolinha de Futebol dentro do CASE \\
\hline Basquete \\
\hline Futsal \\
\hline Vôlei \\
\hline Natação \\
\hline Tênis de Mesa \\
\hline Orientação profissional sobre a importância dos aspectos físico, social e afetivo do esporte. \\
\hline
\end{tabular}

Fonte: Elaborado pelo autor.

A partir dos resultados, foi possível identificar a oferta de conteúdos de esporte disponibilizados aos adolescentes. Entretanto, observa-se a prevalência dos esportes coletivos tradicionais e a falta de diversificação dessas atividades na medida socioeducativa de internação, já apontado por outro estudo no contexto da privação de liberdade (SOUZA, 2018). Para a autora, a não oferta de outras possibilidades esportivas desestimulam os adolescentes em participarem das aulas e, por vezes, somente participam com o intuito de serem bem avaliados no relatório psicossocial elaborado pela Equipe de Referência.

O SINASE (BRASIL, 2006, p. 60) preconiza que os programas que executam as medidas "devem garantir que as atividades esportivas de lazer e culturais previstas no projeto pedagógico sejam efetivamente realizadas, assegurando assim que os espaços físicos destinados às práticas esportivas, de lazer e cultura sejam utilizados pelos adolescentes". Os CASE devem efetivar o Projeto Político Pedagógico, a fim de subsidiar suas ações e garantir a diversificação de tais conteúdos aos adolescentes, seja nas atividades internas quanto nas externas, que muitas vezes são cerceadas pelas concepções exacerbadas de segurança em detrimento das ações pedagógicas, entremeadas nesses espaços de privação de liberdade (ALVES, 2015).

Quanto aos espaços, equipamentos e materiais de esporte, a partir dos conteúdos evidenciados, sugere-se que estes estejam minimamente disponibilizados para a efetivação das atividades. De acordo com o Plano Decenal do Atendimento Socioeducativo do Estado de Mato Grosso (2015/2024) (MATO GROSSO, 2014), 
dos sete CASE existentes à época, três dispunham de espaços e equipamentos adequados para a prática de esportes e de lazer. Contudo, o referido documento não especifica quais as Unidades com espaços adequados a tais práticas.

Os CASE devem oferecer espaços e equipamentos de esporte e de lazer aos adolescentes. Entretanto, por vezes, as atividades acontecem em espaços improvisados, como os pátios das Unidades, denominados como espaço para o 'banho de sol' dos internos, o que está em desacordo com o preconizado pelo SINASE (BRASIL, 2006). Conforme esse dispositivo jurídico, especificamente nos Parâmetros da Gestão Pedagógica no Atendimento Socioeducativo (item 6.2.1), assevera que os programas que executam a medida socioeducativa de internação devem assegurar, dentre outros, o "espaço para prática de esporte e atividades de lazer e cultura devidamente equipados e em quantidade suficiente para o atendimento de todos os adolescentes" (BRASIL, 2006, p. 50). Esse mesmo dispositivo jurídico ainda estabelece nos Parâmetros Arquitetônicos para Unidades de Atendimento Socioeducativo (item 7), que os programas devem prever para o atendimento dos adolescentes, dentre outros, espaços como campo de futebol e quadra poliesportiva coberta.

Ao analisar o acesso dos adolescentes às práticas de esportes anteriores e posteriores à aplicação da medida socioeducativa de internação, mesmo que não garantidas às condições ideais previstas nas legislações vigentes, evidencia-se que a medida socioeducativa de internação no Estado de Mato Grosso foi capaz de propiciar o acesso a tais práticas, haja vista os espaços, equipamentos e conteúdos com orientação profissional disponibilizados nesse contexto. Essa situação pode ser considerada a partir do número de profissionais $(n=21)$ de Educação Física disponíveis para atender os adolescentes no sistema, de acordo com o Plano Decenal de Atendimento Socioeducativo do Estado de Mato Grosso (2015/2024) (MATO GROSSO, 2014), e a exigência desses espaços para as práticas de esporte e atividades de lazer no cumprimento da medida socioeducativa de internação, preconizado pelo SINASE (BRASIL, 2006). A este cenário, alia-se ao fato de os adolescentes também contarem com a orientação de professores de Educação Física advindos das Escolas ligadas a Secretaria de Estado de Educação, responsável pela escolarização formal.

Nesta esteira, um estudo realizado junto a adolescentes em cumprimento de medida socioeducativa de internação no CASE de Cuiabá, identificou que os adolescentes reconhecem que a medida socioeducativa proporcionou maior acesso à escola e, consequentemente, o atendimento na área da saúde, atividades culturais e esportivas (MIRANDA, 2019). Este achado nos remete ao quão restrito é o acesso às práticas esportivas na trajetória desses adolescentes antes da aplicação da medida socioeducativa, sinalizada também por outros estudos (TEJADAS, 2008; SILVA et al., 2008; NOGUEIRA, 2016; TIELLET et al., 2017; ANTUNES; SILVA, 2018).

É oportuno pontuar o alcance que o esporte detém no desenvolvimento humano em diferentes cenários, ocupando posição de destaque em distintas instituições e setores da sociedade (REVERDITO, 2016; REVERDITO et al., 2018; SILVA; MOREIRA, 2018). Estudos de intervenção em contextos de medidas socioeducativas 
que se utilizaram do esporte a partir de seu caráter pedagógico (engajamento em atividade significativa, autorregulação do comportamento, respeito as regras, valores) identificaram o desenvolvimento de competências e atitudes (conexão com os pares, autoeficácia, disposição para envolvimento ativo nas atividades, reconhecimento das diferenças, engajamento social) por parte dos adolescentes, tornando-os sujeitos críticos e capazes de ressignificar suas trajetórias (SANIOTO, 2005; SILVA et al., 2008; TIELLET et al., 2017). No entanto, é fulcral que o ambiente cooperativo, onde as relações interpessoais se desenrolam, sobressaia ao ambiente coercitivo, caracterizado pela imposição de regras, centradas na figura de uma autoridade (MONTAGNER, 2018), frequentemente presenciado no contexto da privação de liberdade, tornando-se um entrave para a prática docente nesses espaços.

Quanto às práticas de lazer disponibilizadas aos adolescentes durante o cumprimento da medida socioeducativa de internação nos CASE do Estado de Mato Grosso, foi possível identificar predominantemente conteúdos inerentes aos interesses artísticos/estético, como aulas de percussão, violão, projetos de cinema, pintura e música, que abrangem todas manifestações artísticas e busca a beleza e o encantamento (MARCELLINO, 1996). Além de outros conteúdos de lazer disponibilizados aos adolescentes, caracterizados pelos interesses físicos (atividades esportivas e recreativas nas aulas de Educação Física) e manuais (confecção de artesanatos e projeto horta), vale destacar a relevância da prática de leitura inerente aos interesses intelectuais nesses espaços de privação de liberdade, por garantir o retorno e acesso à escolarização daqueles que tiveram suas trajetórias marcadas pela evasão e defasagem escolar.

Quadro 2 - Atividades de Lazer evidenciadas na medida socioeducativa

\begin{tabular}{|c|}
\hline Atividades de lazer no recreio dirigido \\
\hline Aulas de percussão \\
\hline Aulas de violão \\
\hline Atividades recreativas nas aulas de Educação Física \\
\hline Jogos pedagógicos \\
\hline Jogos de tabuleiro \\
\hline Jogos pré-desportivos \\
\hline Orientação profissional sobre a importância do lazer \\
\hline Projeções de filmes \\
\hline Projeto cine arte \\
\hline Projeto de pintura \\
\hline Projeto de leitura \\
\hline Projeto horta \\
\hline Projeto de Musicoterapia \\
\hline Torneios de xadrez \\
Confecção de artesanato \\
\hline
\end{tabular}

Fonte: Elaborado pelo autor.

Os dados apresentados elucidam que os adolescentes tiveram um maior acesso aos conteúdos de lazer durante o cumprimento da medida socioeducativa 
de internação, se comparado com a oferta destes em suas trajetórias anteriores. Insta registrar que essa oferta de conteúdos diversificados de lazer com a presença de mediadores (ou animadores socioculturais), deve-se, em grande parte, pelas parcerias que o Sistema Socioeducativo realiza com entidades externas, como a Escola, Instituições religiosas, Instituições de Ensino Superior, Poder Judiciário, dentre outros, garantindo minimamente os aspectos da intersetorialidade preconizada pelo SINASE (BRASIL, 2012).

Constatar que somente após o cometimento de ato infracional e a aplicação da medida socioeducativa estes sujeitos gozem de seus direitos, os quais deveriam ter acesso antes mesmo da aplicação da medida socioeducativa, é no mínimo intrigante do ponto de vista das políticas públicas. Oportuno ponderar que não se trata de desconsiderar a relevância social que as políticas desenvolvidas pelos programas de atendimento socioeducativo detêm no processo de socioeducação desses indivíduos, mas sim em questionar os motivos do fracasso interinstitucional frente as políticas públicas preventivas aos adolescentes, que de certa forma poderiam tolher o cometimento de ato infracional, a partir das relações e reciprocidade que tais ambientes podem ofertar a esses sujeitos, possibilitando superar as adversidades presentes nos contextos os quais estão inseridos (POLETTO; KOLLER, 2008).

De fato, é evidente que os conteúdos de lazer estão minimamente garantidos aos adolescentes no contexto pesquisado. Marcelino (1996) destaca que os aspectos da atitude, relacionado à forma que o sujeito interage e satisfaz com a atividade, e o tempo, inerente ao tempo disponível das obrigações sociais, aliados ao caráter lúdico e de livre escolha, circundam e caracterizam as atividades do lazer. Nesse sentido, considerando as relações de poder que permeiam tais atividades nesses contextos (CONCEIÇÃO, 2012; NOGUEIRA, 2016; SOUZA, 2018), difícil seria imaginar a livre escolha das atividades e um ambiente lúdico onde os adolescentes são vigiados 24 horas do dia.

A relação entre a livre escolha das atividades e ambiente lúdico é destacado no estudo de Oliveira e Gomes (2008). Ao analisarem os jogos e brincadeiras dos adolescentes privados de liberdade em um CASE do Estado de Mato Grosso, os autores observaram que os adolescentes percebem a quadra, piscina, pátio e sala de aula, como espaços disponíveis para se jogar. Entretanto, quando questionados sobre os espaços que mais brincavam/jogavam, responderam que os faziam no quarto/cela. Provavelmente por se tratar de um espaço fechado, onde a vigilância não se faz a todo o momento, conseguiam por alguns instantes se entregarem ao jogo.

Outra problemática que se configura como entrave nos processos educativos do lazer no contexto da privação de liberdade é a retirada das atividades como punição para os adolescentes considerados indisciplinados (CONCEIÇÃO, 2012). Esta prática está em desacordo com os dispositivos jurídicos inerentes ao atendimento socioeducativo, que garantem a oferta dessas atividades no processo de socioeducação. No Estado de Mato Grosso, a partir da normatização do Conselho Socioeducador, formado por profissionais de diferentes perfis, com o objetivo de analisar e deliberar sobre as sanções aplicáveis aos adolescentes que cometem 
infrações nos CASE, houve o entendimento de que as atividades escolares, culturais, esportivas e de lazer, não devem ser retiradas, respeitando a legislação vigente e garantindo minimamente $o$ acesso as ações pedagógicas disponibilizadas.

\section{CONCLUSÃO}

A presente pesquisa evidencia a escassez de políticas de atendimento intersetorial ao adolescente, intimamente relacionada à falta de articulação da rede de proteção. Nota-se que o perfil dos sujeitos da pesquisa representa uma grande parcela da sociedade brasileira, que na atual conjuntura do país é alcançada por um sistema político e econômico excludente. A partir das categorias de análise concluise que, em relação às trajetórias dos adolescentes, o cumprimento da medida socioeducativa de internação no estado de Mato Grosso consegue assegurar maior acesso às práticas de esporte e de lazer, seja pelo repertório de conteúdos com orientação profissional e/ou espaços e equipamentos disponibilizados nos CASE, considerando os Parâmetros da Gestão Pedagógica no Atendimento Socioeducativo disposto no SINASE. Tal conclusão revela obstáculos para o acesso às políticas de esporte e lazer na trajetória dos sujeitos da pesquisa, anterior ao ingresso no sistema, o que se agrava ainda mais com a constatação dos altos índices de evasão escolar desses adolescentes.

Consideramos como limitações deste estudo a ausência da análise das práticas pedagógicas dos profissionais de Educação Física no contexto da privação de liberdade e, também, o fato das manifestações dos adolescentes sobre as práticas de esporte e lazer em suas trajetórias serem autodeclarativas e transcritas para o PIA. Assim, faz-se necessário à produção de novos estudos, sobretudo em relação as práticas pedagógicas desenvolvidas nesses espaços de privação de liberdade, bem como investigar in loco os contextos dos quais são advindos esses adolescentes em cumprimento de medida socioeducativa de internação.

Este estudo oferece informações que poderão subsidiar a articulação dos entes federativos no que tange à elaboração de políticas preventivas de atendimento ao adolescente. O esporte e lazer em suas múltiplas dimensões, reconhecidos como direito social e tratados pedagogicamente, poderão oferecer aos jovens a oportunidade para mudar o curso de suas vidas e dos ambientes em que estão inseridos.

\section{REFERÊNCIAS}

ALVES, Juliano Cláudio. 0 olhar dos agentes socioeducativos sobre as ações pedagógicas e os adolescentes da unidade de internação de Cáceres/MT. 2015. 118f. Dissertação (Mestrado em Educação) - Programa de Pós-Graduação em Educação da Universidade do Estado de Mato Grosso, Cáceres, 2015. Disponível em: http://portal. unemat.br/media/oldfiles/educacao/docs/dissertacao/2015/Juliano_Claudio_Alves.pdf. Acesso em: 04 out. 2019. 
ANTUNES, Scheila Espindola; SILVA, Otávio Guimarães Tavares da. O esporte na ressocialização de jovens em conflito com a lei: um estudo de caso. Pensar a Prática, v. 21, n. 1, p. 168-177, jan./mar. 2018. Disponível em: https://www.revistas.ufg.br/fef/article/ view/46586/pdf. Acesso em: 3 jan. 2019.

ASSIS, Simone Gonçalves de; CONSTANTINO, Patrícia. Perspectivas de prevenção da infração juvenil masculina. Ciência \& Saúde Coletiva, v. 10, n. 1, p. 81-90, jan./mar. 2005. Disponível em: http://www.scielo.br/pdf/csc/v10n1/a08v10n1.pdf. Acesso em: 19 fev. 2019.

BARDIN, Laurence. Análise de conteúdo. São Paulo: Edições 70, 2011.

BAZON, Marina Resende; SILVA, Jorge Luiz da; FERRARI, Renata Martins. Trajetórias escolares de adolescentes em conflito com a lei. Educação em Revista, v. 29, n. 2, p. 175199, jun. 2013. Disponível em: http://www.scielo.br/pdf/edur/v29n2/08.pdf. Acesso em: 12 abr. 2019.

BRASIL. Lei no 8.069, de 13 de julho de 1990. Dispõe sobre o Estatuto da Criança e do Adolescente e dá outras providências. Diário Oficial da União, Brasília, 13 de jul. de 1990. Disponível em: http://www.planalto.gov.br/ccivil_03/leis/l8069.htm. Acesso em: 20 jan. 2020.

BRASIL. Conselho Nacional dos Direitos da Criança e Adolescente. Sistema Nacional de Atendimento Socioeducativo - SINASE. Brasília - DF: CONANDA, 2006. Disponível em: http://www.conselhodacrianca.al.gov.br/sala-de-imprensa/publicacoes/sinase.pdf. Acesso em: 18 jan. 2020.

BRASIL. Lei 12.594, de 18 de janeiro de 2012. Institui o Sistema Nacional de Atendimento Socioeducativo (Sinase) e regulamenta [...]. Diário Oficial da União, Brasília, 19 de jan. 2012. Disponível em: http://www.planalto.gov.br/ccivil 03/ Ato2011-2014/2012/Lei/L12594. htm. Acesso em: 20 jan. 2020.

BRASIL. Secretaria Nacional dos Direitos da Criança e do Adolescente. Relatório Anual do SINASE 2017. Brasília, 2019. Disponível em: https://www.gov.br/mdh/pt-br/navegue-portemas/crianca-e-adolescente/LevantamentoAnualdoSINASE2017.pdf. Acesso em: 29 fev. 2020.

CARNEIRO, Kleber Tuxen et al. Sobre lazer e possibilidades formativas em adolescentes que cumprem medidas socioeducativas. Pensar a Prática, v. 19, n. 4, p. 867-880, out./dez. 2016. Disponível em: https://www.revistas.ufg.br/fef/article/view/39672/pdf. Acesso em: 07 jan. 2019.

CONCEIÇÃO, Willian Lazaretti da. Lazer e adolescente em privação de liberdade: um diálogo possível?. 2012. 145f. Dissertação (Mestrado em Educação) - Programa de Pós-Graduação em Educação, Universidade Federal de São Carlos, São Carlos/ SP, 2012. Disponível em: https://repositorio.ufscar.br/bitstream/handle/ufscar/2630/4535. pdf?sequence=1\&isAllowed=y. Acesso em: 27 jan. 2019.

DIAS, Aline Fávaro; ONOFRE, Elenice Maria Cammarosano. A relação do jovem em conflito com a lei e a escola. Impulso, v. 20, n. 49, p. 31-42, jan./jun. 2010. Disponível em: https:// www.metodista.br/revistas/revistas-unimep/index.php/impulso/article/view/870/471. Acesso em: 21 set. 2019.

DIB, Marina Azôr; BAZON, Marina Rezende; SILVA, Jorge Luiz da. Família e conduta infracional na adolescência: revisão sistemática da literatura. Perspectivas em Psicologia, v. 16, n. 1, p.142-159, jan./jun. 2012. Disponível em: http://www.seer.ufu.br/index.php/ perspectivasempsicologia/article/view/27553/15107. Acesso em: 15 nov. 2019. 
DOMINGOS, Rosangela da Silva. Pensando e praticando o esporte na medida socioeducativa: orientações para profissionais de educação física. 2014. 152f. Dissertação (Mestrado em Adolescente em Conflito com a Lei) - Universidade Anhanguera de São Paulo, São Paulo, 2014. Disponível em: https://repositorio.pgsskroton.com/ bitstream/123456789/3330/1/Rosangela\%20da\%20Silva\%20Domingos.pdf. Acesso em: 13 fev. 2019.

FEIJÓ, Maria Cristina; ASSIS, Simone Gonçalves. O contexto de exclusão social e de vulnerabilidade de jovens infratores e de suas famílias. Estudos de Psicologia, v. 9, n. 1, p. 157-166, abr. 2004. Disponível em: http://www.scielo.br/pdf/epsic/v9n1/22391.pdf. Acesso em: 18 out. 2019.

GADEA, Carlos Alfredo et al. Trajetórias de jovens em situação de vulnerabilidade social: sobre a realidade juvenil, violência intersubjetiva e políticas para jovens em Porto Alegre RS. Sociologias, v. 19, n. 45, p. 258-299, maio/ago. 2017. Disponível em: http://www.scielo. br/pdf/soc/v19n45/1517-4522-soc-19-45-00258.pdf. Acesso em: 08 jan. 2020.

GALLO, Alex Eduardo; WILLIAMS, Lúcia Cavalcante de Albuquerque. A escola como fator de proteção à conduta infracional de adolescentes. Cadernos de Pesquisa, v. 38, n. 133, p. 41-59, jan./abr. 2008. Disponível em: http://www.scielo.br/pdf/cp/v38n133/a03v38n133.pdf. Acesso em: 16 nov. 2019.

GIL, Antônio Carlos. Métodos e Técnicas de Pesquisa Social. 6. ed. São Paulo: Atlas, 2008.

JIMENEZ, Luciene; MARQUES, Vanda Regina. Revisão integrativa sobre a prática infracional na adolescência (2005/2014). Estudos da Psicologia, v. 23, n. 2, p. 111-121, abr./jun. 2018. Disponível em: http://pepsic.bvsalud.org/pdf/epsic/v23n2/a03v23n2.pdf. Acesso em: 09 jan. 2020.

KOSTULSKI, Camila Almeida et al. Adolescência, violência e invisibilidade social: uma revisão crítica a partir da história de Sandro. Revista Sociais \& Humanas, v. 32, n. 3, p. 161-172, 2019. Disponível em: https://periodicos.ufsm.br/sociaisehumanas/article/ view/26823/pdf. Acesso em: 25 fev. 2020.

MACHADO, Gisele Viola et al. A análise da Evolução das Políticas Públicas em Esporte Educacional no Brasil. Revista Ciências Humanas - UNITAU, v. 10, n. Extra, p. 103-115, out. 2017. Disponível em: https://www.rchunitau.com.br/index.php/rch/article/view/406/228. Acesso em: 04 jan. 2020.

MACHADO, Gisele Viola; GALATTI, Larissa Rafaela; PAES, Roberto Rodrigues. Seleção de conteúdos e procedimentos pedagógicos para o ensino do esporte em projetos sociais: reflexões a partir dos jogos esportivos coletivos. Motrivivência, n. 39, p. 164-176, dez. 2012. Disponível em: https://periodicos.ufsc.br/index.php/motrivivencia/article/view/21758042.2012v24n39p164/23401. Acesso em: 11 maio 2019.

MARCELLINO, Nelson Carvalho. Estudos do Lazer: uma introdução. Campinas: Autores Associados, 1996.

MARCELLINO, Nelson Carvalho. Lazer e Educação. 4. ed. Campinas: Papirus, 1998.

MARCELLINO, Nelson Carvalho; BARBOSA, Felipe Soligo; MARIANO, Stéphanie Helena. As cidades e o Acesso aos Espaços e Equipamentos de Lazer. Impulso, v.17, n. 44, p. 5566, 2006.

MARCELLINO, Nelson Carvalho et al. Políticas Públicas de Lazer - formação e desenvolvimento de pessoal: os casos de Campinas e Piracicaba-SP. Curitiba: OPUS, 2007. Disponível em: https://repositorio.ufsc.br/bitstream/handle/123456789/128012/ politicasPublicas.pdf?sequence=1. Acesso em: 28 jan.2020. 
MARIANO, Stéphanie Helena; MARCELLINO, Nelson Carvalho. Animação sociocultural em cidades pequenas da região metropolitana de campinas (SP). Revista Mackenzie de Educação Física e Esporte, v. 10, n. 2, p. 74-86, 2011. Disponível em: http:// editorarevistas.mackenzie.br/index.php/remef/article/view/3517. Acesso em: 08 set. 2019.

MATO GROSSO. Plano Decenal de Atendimento Socioeducativo do Estado de Mato Grosso (2015-2024). Cuiabá: Governo do Estado de Mato Grosso, 2014. Disponível em: http://www.sesp.mt.gov.br/documents/4713378/12088987/Plano+Decenal Salvo+em+1 122014 Itima+verso+\%282\%29.pdf. Acesso em: 28 jan.2020.

MIRANDA; Kátia Aparecida da Silva Nunes. Processos educativos vivenciados pelos jovens em situação de privação de liberdade. In: BELTRÃO, Márcio Evaristo; BARROS, Solange Maria de. (org.). Transgressão como prática de resistência: um olhar crítico sobre os estudos Queer e a socioeducação. Cuiabá: EdUFMT, 2019. p. 133-162.

MONTAGNER, Paulo Cesar. Estudos em Pedagogia do Esporte: posicionamentos em defesa do esporte de crianças e jovens. In: BENTO, Jorge O.; MOREIRA, Wagner W.; LOUREIRO, Adriano C.; BENTO; Helena C.; BOTELHO, Rafael G.; MARINHO, Teresa C. (org.). Cuidar da casa comum: Da natureza, da vida, da humanidade. Oportunidades e responsabilidades do Desporto e da Educação Física. Belo Horizonte: Casa da Educação Física, 2018. v. 1. p. 117-142. Disponível em: http://cev.org.br/arquivo/biblioteca/4041560. pdf. Acesso em: 26 jan. 2020.

NOGUEIRA, Thais de Souza. A relação entre cultura, esporte, lazer e a medida socioeducativa de internação no Centro Socioeducativo Feminino - CESEF/PARÁ, de 2006 a 2014. 2016. 70f. Dissertação (Mestrado em Psicologia) - Programa de PósGraduação em Psicologia da Universidade Federal do Pará, Belém, 2016. Disponível em: http://cev.org.br/arquivo/biblioteca/4040638.pdf. Acesso em: 16 jan. 2019.

NUNES, Mikaella Cristina Antunes; ANDRADE, Anne Graça de Sousa; MORAIS, Normanda Araújo de. Adolescentes em conflito com a lei e família: um estudo de revisão sistemática da literatura. Contextos Clínicos, v. 6, n. 2, p. 144-156, jul./dez. 2013. Disponível em: http:// pepsic.bvsalud.org/pdf/cclin/v6n2/v6n2a08.pdf. Acesso em: 10 jun. 2019.

OLIVEIRA, Renata Hoeflich Damaso de; TURECK, Lucia Terezinha Zanato. A invisibilidade social e a prática do ato infracional na adolescência: possíveis correlações. Revista Educação e Cultura Contemporânea, v. 16, n. 45, p. 460-477, 2019. Disponível em: http:// periodicos.estacio.br/index.php/reeduc/article/view/4332/47966102. Acesso em: 08 mar. 2020.

OLIVEIRA, Sônia Cristina de; GOMES, Cleomar Ferreira. Os jogos e brincadeiras de adolescentes privados de liberdade: Uma possibilidade na prática educativa. Revista da Faculdade de Educação, n. 9, p. 115-128, jan./jun. 2008.

OLIVERA, Raul Angel Carlos; OLIVEIRA, Ueliton Peres de. Modelo simples de crime racional: modelagem econométrica do perfil socioeconômico de adolescentes em conflito com a lei. In: FERNANDES, Maria Nilvane; COSTA, Ricardo Peres da. (org.). Coletânea Socioeducação no Brasil: intersetorialidade, desafios e referências para o atendimento. Curitiba: Nova Práxis, 2019. v. 4. p. 214-232.

PAES, Roberto Rodrigues; BALBINO, Hermes Ferreira. A pedagogia do esporte e os jogos coletivos. In: ROSE JUNIOR, Dante de. (org.). Esporte e atividade física na infância e adolescência: uma abordagem multidisciplinar. 2. ed. Porto Alegre: Artmed, 2009. p. 73-83.

PIZANI, Rafael Stein; AMARAL, Silvia Cristina Franco; PAES, Roberto Rodrigues. Esporte e lazer: diálogos possíveis à luz da pedagogia do esporte. Licere, v. 15, n. 3, p. 1-18, set. 2012. Disponível em: https://periodicos.ufmg.br/index.php/licere/article/view/717/518. Acesso em: 16 jul. 2019. 
POLETTO, Michele; KOLLER, Silvia Helena. Contextos ecológicos: promotores de resiliência, fatores de risco e de proteção. Estudos de Psicologia, v. 25, n. 3, p. 405-416, jul./set. 2008. Disponível em: https://www.scielo.br/pdf/estpsi/v25n3/a09v25n3.pdf. Acesso em: 27 ago. 2019.

REVERDITO, Riller Silva. Pedagogia do esporte e modelo bioecológico do desenvolvimento humano: indicadores para avaliação de impacto em programa socioesportivo. 2016. 209f. Tese (Doutorado em Educação Física) - Programa de Pósgraduação em Educação Física, Universidade Estadual de Campinas, Campinas, 2016. Disponível em: http://repositorio.unicamp.br/bitstream/REPOSIP/322128/1/Reverdito RillerSilva_D.pdf. Acesso em: 26 mar. 2018.

REVERDITO, Riller Silva et al. Espaços e equipamentos disponíveis para o lazer: possibilidades da criança ao jogo na cidade de Hortolândia-SP. Licere, v. 15, n. 3, p. 1-24, set. 2012. Disponível em: https://periodicos.ufmg.br/index.php/licere/article/view/714/515. Acesso em: 11 jan. 2020.

REVERDITO, Riller Silva et al. O esporte na ecologia do desenvolvimento humano: desafios da pesquisa e intervenção no Brasil. In: BENTO, Jorge O.; MOREIRA, Wagner W.; LOUREIRO, Adriano C.; BENTO; Helena C.; BOTELHO, Rafael G.; MARINHO, Teresa C. (org.). Cuidar da casa comum: da natureza, da vida, da humanidade. Oportunidades e responsabilidades do Desporto e da Educação Física. Belo Horizonte: Casa da Educação Física, 2018. v. 1, p. 203-215. Disponível em: http://cev.org.br/arquivo/biblioteca/4041560. pdf. Acesso em: 26 jan.2020.

REVERDITO, Riller Silva et al. Pedagogia do Esporte: possibilidades para o convívio com o esporte no contexto escolar. In: SILVA, Junior Vagner Pereira da; GONÇALVES-SILVA, Luiza Lana; MOREIRA, Wagner Wey. (org.). Educação Física e seus diversos olhares. Campo Grande: Editora da UFMS, 2016ª v.1, p. 55-76.

REVERDITO, Riller Silva et al. O Programa Segundo Tempo em municípios brasileiros: indicadores de resultado no macrossistema. Journal of Physical Education, v. 27, n.1, p. 1-14, out. 2016b. Disponível em: http://periodicos.uem.br/ojs/index.php/RevEducFis/article/ view/31303/18006. Acesso em: 27 out. 2019.

SANIOTO, Henrique. Contribuindo para a formação humana dos adolescentes da FEBEM por meio da Ginástica Geral. 2005. 198f. Dissertação (Mestrado em Educação Física) - Programa de Pós-graduação em Educação Física, Universidade Estadual de Campinas, Campinas, 2005. Disponível em: http://repositorio.unicamp.br/handle/ REPOSIP/274914. Acesso em: 18 jan. 2019.

SCAGLIA, Alcides José; REVERDITO, Riller Silva; GALATTI, Larissa Rafaela. A Contribuição da Pedagogia do Esporte ao Ensino do Esporte na Escola: tensões e reflexões metodológicas. In: MARINHO, Alciane; NASCIMENTO, Juares Vieira do; OLIVEIRA, Amauri Aparecido Bássoli. (org.). Legados do Esporte Brasileiro. Florianópolis: UDESC, 2014. v. 1. p. 45-86. Disponível em: http://memoriadasolimpiadas.rb.gov.br/jspui/ bitstream/123456789/1037/1/MARINHO.LEGADO.2014.pdf. Acesso em: 22 jan.2020.

SILVA, Fábio Silvestre et al. Futebol Libertário: compromisso social na medida. Psicologia Ciência e Profissão, v. 28, n. 4, p. 832-845, out. 2008. Disponível em: http://www.scielo.br/ pdf/pcp/v28n4/v28n4a14.pdf. Acesso em: 12 jan. 2019.

SILVA, Jorge Luiz da; BAZON, Marina Rezende. Revisão sistemática de estudos sobre os aspectos escolares relacionados ao cometimento de delitos. Psicologia em Revista, v. 21, n. 2, p. 273-292, ago. 2015. Disponível em: http://pepsic.bvsalud.org/pdf/per/v21n2/ v21n2a05.pdf. Acesso em: 19 set. 2019. 
SILVA, Junior Vagner Pereira da; MOREIRA Wagner Wey. Lazer e Esporte no Século XXI: novidades no horizonte? Curitiba: InterSaberes, 2018.

SOUZA, Caroline Maciel. Educação Física na medida socioeducativa de internação: Um estudo sobre práticas educativas e mecanismos de resistência. 2018. 191f. Dissertação (Mestrado em Educação) - Programa de Pós-Graduação em Educação, Universidade Federal de São Carlos, São Carlos, 2018. Disponível em: https://repositorio.ufscar.br/ bitstream/handle/ufscar/9704/SOUZA Carolina 2018. pdf?sequence=4\&isAllowed=y. Acesso em: 06 fev. 2019.

TEJADAS, Silvia da Silva. Juventude e Ato Infracional. Porto Alegre: EDIPUCRS, 2008.

TIELLET, Maria do Horto Salles et al. Ações de extensão em um centro de atendimento socioeducativo do Estado de Mato Grosso. EDUCA - Revista Multidisciplinar em Educação, v. 4, n. 9, p. 65-78, set./dez. 2017. Disponível em: http://www.periodicos.unir.br/ index.php/EDUCA/article/view/2132/2141. Acesso em: 17 jan. 2019.

TRENTIN, Dayane Ferraz Lacerda; SILVESTRE, Bruno Modesto; AMARAL, Sílvia Cristina Franco. Juventudes e medida socioeducativa: O olhar dos Agentes Pedagógicos sobre as práticas de lazer. Pensar a Prática, v. 21, n. 4, p. 877-889, out./dez. 2018. Disponível em: https://www.revistas.ufg.br/fef/article/view/50848/pdf. Acesso em: 27 jan. 2019.

ZAPPE, Zane Gonçalves; RAMOS, Nara Vieira. Perfil de adolescentes privados de liberdade em Santa Maria/RS. Psicologia \& Sociedade, v.22, n. 2, p. 365-373, maio/ago. 2010. Disponível em: http://www.scielo.br/pdf/psoc/v22n2/17.pdf. Acesso em: 05 fev. 2020. 
Abstract: This research aims to understand the access to sports and leisure in adolescents' lives in compliance with court-mandated social-educative internment in the state of Mato Grosso. Thirty-six Individual Care Plans of seven SocioEducational Care Centers were examined, which had been created between 20172018 and publicized by the State Management of the System for Childhood and Adolescence - SIPIA/SINASE/MT. Data related to sports and leisure were submitted to content analysis. The adolescents' profiles show today's socioeconomic problems and social vulnerability. Based on the categories of analysis, the offer of these care policies in the adolescents' lives was observed to be restricted. Compliance to courtmandated social-educative internment is found to provide greater access to sports and leisure spaces, equipment and contents to the adolescents when compared to their experiences before the sentence.

Keywords: Adolescent. Sports. Leisure Activities. Social vulnerability.

Resumen: Este estudio tiene por objetivo comprender el acceso al deporte y a la recreación de adolescentes que cumplen medidas socioeducativas de internación en el Estado de Mato Grosso. Se analizaron 36 Planes Individuales de Asistencia (PIA) de siete Centros de Asistencia Socioeducativa, elaborados en los años 2017 y 2018 y puestos a disposición por la Administración Estatal del Sistema para la Infancia y Adolescencia - SIPIA/SINASE/MT. Los datos relacionados a los ejes deportes y recreación se analizaron a través de la metodología de análisis de contenido. El perfil de los adolescentes retrata los problemas socioeconómicos y de vulnerabilidad social presentes actualmente. A partir de las categorías de análisis, se observó una oferta limitada de estas políticas de asistencia en la trayectoria de los adolescentes. Se concluye que el cumplimiento de medidas socioeducativas de internación propició un mayor acceso a los espacios y contenidos de deporte y recreación a los adolescentes, en comparación con sus experiencias previas a la aplicación de las medidas.

Palabras clave: Adolescente. Deportes. Actividades recreativas. Vulnerabilidad Social 


\section{LICENÇA DE USO}

Este é um artigo publicado em acesso aberto (Open Access) sob a licença Creative Commons atribuição Não Comercial 4.0 (CC BY-NC 4.0), que permite uso, distribuição e reprodução em qualquer meio, desde que o trabalho original seja corretamente citado, com a restrição que impede o uso para fins comerciais. Mais informações em: http://creativecommons.org/licenses/by-nc/4.0

\section{CONFLITO DE INTERESSES}

Os autores declararam que não há conflito de interesses neste trabalho.

\section{CONTRIBUIÇÕES AUTORAIS}

Ueliton Peres de Oliveira realizou a coleta dos dados; analisou os dados e desenvolveu o documento no formato do artigo;

Willian Lazaretti da Conceição realizou a revisão do documento no formato de artigo; participou da análise e discussão dos dados; Colaboração com o referencial teórico;

José Tarcísio Grunennvaldt realizou a revisão do documento no formato de artigo; participou da análise e discussão dos dados;

Raul Angel Carlos Olivera realizou a revisão do documento no formato de artigo; participou da análise e discussão dos dados; Colaboração com o referencial teórico; Riller Silva Reverdito orientou o desenvolvimento do artigo; colaborou com a metodologia, análise e discussão dos dados.

\section{FINANCIAMENTO}

Este trabalho teve apoio de: Centro de Desenvolvimento de Pesquisa em Políticas de Esporte e de Lazer da Rede Cedes do Estado de Mato Grosso; Ministério da Cidadania, Secretaria Especial do Esporte/Secretaria Nacional de Esporte, Educação, Lazer e Inclusão Social (SNELIS); Centro Interdisciplinar de Pesquisas em Esporte e Exercício Físico (CIPEEF), Universidade do Estado de Mato Grosso.

\section{ÉTICA EM PESQUISA}

A pesquisa foi submetida ao Comitê de Ética em Pesquisa - CEP/SAÚDE/UFMT (CAAE: 03382918.9.0000.8124) e aprovada conforme parecer $n^{\circ} 3.102 .411$.

\section{COMO REFERENCIAR}

OLIVEIRA, Ueliton Peres de et al. Esporte e lazer no plano individual de atendimento de adolescentes em cumprimento de medida socioeducativa de internação. Movimento, n. 26, p. e26054, jan./dez. 2020. Disponível em: https:// www.seer.ufrgs.br/Movimento/article/view/101588. Acesso em: 23 jul. 2020. DOI: https://doi.org/10.22456/1982-8918.101588.

\section{RESPONSÁVEIS EDITORIAIS}

Alex Branco Fraga*, Elisandro Schultz Wittizorecki*, Ivone Job*, Mauro Myskiw*, Raquel da Silveira*

*Universidade Federal do Rio Grande do Sul, Escola de Educação Física, Fisioterapia e Dança, Porto Alegre, RS, Brasil 